\title{
The effect of lutein- and zeaxanthin-rich foods $v$. supplements on macular pigment level and serological markers of endothelial activation, inflammation and oxidation: pilot studies in healthy volunteers
}

\author{
Ryan Graydon $^{1} \dagger$, Ruth E. Hogg ${ }^{2 *} \dagger$, Usha Chakravarthy ${ }^{2}$, Ian S. Young ${ }^{1}$ and Jayne V. Woodside ${ }^{1}$ \\ ${ }^{1}$ Nutrition and Metabolism Group, Centre for Public Health, Queen's University Belfast, Belfast BT12 6BJ, \\ Northern Ireland, UK \\ ${ }^{2}$ Institute of Clinical Sciences, Centre for Vision Sciences, Royal Victoria Hospital, Queen's University Belfast, \\ Grosvenor Road, Belfast BT12 6BA, Northern Ireland, UK
}

(Submitted 4 March 2011 - Final revision received 14 September 2011 - Accepted 14 September 2011 - First published online 7 February 2012)

\section{Abstract}

The aim of the present study was to compare the effect of lutein- and zeaxanthin-rich foods and supplements on macular pigment level (MPL) and serological markers of endothelial activation, inflammation and oxidation in healthy volunteers. We conducted two 8-week intervention studies. Study 1 ( $n$ 52) subjects were randomised to receive either carrot juice (a carotene-rich food) or spinach powder (a lutein- and zeaxanthin-rich food) for 8 weeks. Study 2 subjects $(n 75)$ received supplements containing lutein and zeaxanthin, $\beta$-carotene, or placebo for 8 weeks in a randomised, double-blind, placebo-controlled trial. MPL, serum concentrations of lipid-soluble antioxidants, inter-cellular adhesion molecule 1 , vascular cell adhesion molecule 1 , C-reactive protein and $\mathrm{F}_{2}$-isoprostane levels were assessed at baseline and post-intervention in both studies. In these intervention studies, no effects on MPL or markers of endothelial activation, inflammation or oxidation were observed. However, the change in serum lutein and zeaxanthin was associated or tended to be associated with the change in MPL in those receiving lutein- and zeaxanthin-rich foods (lutein $r 0 \cdot 40, P=0 \cdot 05$; zeaxanthin $r 0 \cdot 30, P=0 \cdot 14$ ) or the lutein and zeaxanthin supplement (lutein $r 0.43, P=0.03$; zeaxanthin $r 0 \cdot 22, P=0 \cdot 28$ ). In both studies, the change in MPL was associated with baseline MPL (food study $r-0.54, P<0.001$; supplement study $r-0.40, P<0 \cdot 001$ ). We conclude that this 8 -week supplementation with lutein and zeaxanthin, whether as foods or as supplements, had no significant effect on MPL or serological markers of endothelial activation, inflammation and oxidation in healthy volunteers, but may improve MPL in the highest serum responders and in those with initially low MPL.

\section{Key words: Lutein: Zeaxanthin: $\beta$-Carotene: Macular pigment level: Inflammation: Oxidation}

Age-related macular degeneration (AMD) is the leading cause of blindness in many developed countries, including the $\mathrm{UK}^{(1)}$. The role of diet in modulating AMD risk has received much attention; and higher intakes of carotenoids and other micronutrients have been associated with reduced risk of the disease $^{(2-6)}$, while a supplement containing an antioxidant 'cocktail' of vitamin $\mathrm{C}$, vitamin $\mathrm{E}, \boldsymbol{\beta}$-carotene, $\mathrm{Zn}$ and $\mathrm{Cu}$ was shown to reduce the risk of advanced AMD by approximately $25 \%$ in the Age-Related Eye Disease Study (AREDS) ${ }^{(7)}$. The macular pigment is made up of the xanthophylls, lutein, zeaxanthin and meso-zeaxanthin, and low macular pigment level (MPL) has been related to AMD risk $^{(8)}$. Lutein and zeaxanthin have been shown to be potent antioxidants ${ }^{(9,10)}$ and their location in the retina enables them to protect the lipid bio-layers. AMD is increasingly being understood in terms of inflammatory processes, as many of the genes known to increase the risk are involved in the complement system ${ }^{(11-13)}$. Dietary micronutrients have also been shown to be associated with inflammation. Carotenoid-rich foods have been shown to reduce C-reactive protein (CRP) concentrations, within the normal range of CRP in healthy humans ${ }^{(14)}$, while serum levels of $\beta$-carotene have been shown to be inversely associated with inflammatory markers, including CRP, although it is not clear whether the carotenoids reduce inflammation or whether the inflammation suppresses carotenoid status ${ }^{(15)}$. Animal models have been used to show that lutein and zeaxanthin also have the capacity to reduce inflammation ${ }^{(16,17)}$, although this is yet to be confirmed in studies involving human subjects.

Abbreviations: AMD, age-related macular degeneration; CRP, C-reactive protein; ICAM-1, inter-cellular adhesion molecule 1; MPL, macular pigment level; VCAM-1, vascular cell adhesion molecule 1.

*Corresponding author: Dr R. E. Hogg, fax +44 2890632699 , email r.e.hogg@qub.ac.uk

† R. Graydon \& R. E. Hogg are joint first authors. 
Therefore, carotenoids may contribute to AMD prevention by both increasing MPL and exerting an antioxidant and anti-inflammatory effect on the surrounding retinal tissue. Evidence for lutein and zeaxanthin contributing to AMD prevention has been shown in case-control studies ${ }^{(4)}$ and cohort studies $^{(2,18)}$. However, there have been few large intervention studies examining the effect of increased lutein and zeaxanthin intake on MPL and AMD progression.

Findings from intervention studies involving antioxidants have shown the potentially different effects of antioxidantrich foods $v$. supplements. In a number of prospective cohort studies, those with the highest vitamin $\mathrm{E}$ levels were found to have a significantly lower risk of $\mathrm{CHD}^{(19,20)}$; however, supplementation trials involving vitamin $\mathrm{E}$, either singly, or in combination with other antioxidants have yielded disappointing results, largely showing that they do not markedly reduce cardiovascular events or cancer ${ }^{(21,22)}$. It may be that isolated large single antioxidant supplement doses do not have significant health benefits, and that a fruit- and vegetable-rich diet may be more effective. Therefore, in the first study, a lutein- and zeaxanthin-rich food was compared to a $\beta$-carotene-rich food (food study) and, in the second study, a lutein and zeaxanthin supplement was compared with a $\beta$-carotene supplement or placebo (supplement study). We hypothesised that increased dietary intake of lutein and zeaxanthin, whether as foods or as supplements, would increase MPL in healthy volunteers and also reduce the markers of endothelial activation (inter-cellular adhesion molecule 1 (ICAM-1); vascular cell adhesion molecule (VCAM-1), inflammation (CRP) and oxidation (urinary isoprostanes). A $\beta$-carotene-rich food and supplement was included in the study design because of its previously documented association with inflammation ${ }^{(15)}$.

\section{Materials and methods}

Ethics

This study was conducted according to the guidelines laid down in the Declaration of Helsinki and all procedures involving human subjects/patients were approved by the Research Ethics Committee of the School of Medicine and Dentistry, Queen's University Belfast. Written informed consent was obtained from all subjects/patients.

\section{Subjects}

Subjects were healthy male and female volunteers, recruited from the university staff and students, hospital staff and the general public. For each study, the protocol was explained in full to all subjects and written informed consent was obtained. Volunteers were screened and included in the study if they were male or female, and aged between 18 and 75 years, and excluded from the study if they suffered from age-related macular degeneration, any other eye disease affecting MPL assessment or if they were already taking carotenoid supplements.

At the start and end of the study, participants filled in a 4-d food diary (both 1 weekend day and 3 week-days). Energy and nutrient intakes were calculated by entering the dietary data onto an extensive computerised food analysis database based on UK food composition tables (WISP, Tinuviel Software, Warrington, UK).

\section{Food study}

This study was an 8-week randomised intervention study using dried spinach powder (a lutein- and zeaxanthin-rich food; Martin Speciality Foods, Belfast, UK) or carrot juice (a $\beta$-carotenerich food; Schoenenberger Walther Pflanzensaftwerk GmbH, Magstadt, Germany).

Subjects were randomised, by random number generation, with a block design (block size $=4$ ), to either dried spinach powder $(10.4 \mathrm{~g})$ daily or carrot juice $(131 \mathrm{ml})$ daily for 8 weeks. Dried spinach powder $(10 \cdot 4 \mathrm{~g})$ daily provided each volunteer with $15 \mathrm{mg}$ of lutein and zeaxanthin (95\% lutein), and $131 \mathrm{ml}$ of carrot juice provided each volunteer with $15 \mathrm{mg}$ of $\beta$-carotene daily (amounts confirmed by food analysis; $\left.\mathrm{Craft}^{(23)}\right)$. The spinach powder also contained approximately $2 \mathrm{mg} \quad \beta$-carotene/d. The pre- and postsupplementation clinic protocol followed is detailed in the 'Clinical protocol' subsection.

\section{Supplement study}

This study was an 8-week double-blind, placebo-controlled intervention study. Volunteers were randomised to either a mixed lutein and zeaxanthin supplement (containing $5 \mathrm{mg}$ zeaxanthin and $10 \mathrm{mg}$ lutein; Life Extension Foundation, Fort Lauderdale, FL, USA), a 15-mg $\beta$-carotene supplement (Holland \& Barrett, Nuneaton, UK) or placebo (lactose powder in a gelatine capsule, supplied by Victoria Pharmaceuticals, Belfast, UK). Volunteers were randomised as previously described, but this time in blocks of nine subjects. The same pre- and post-supplementation clinic protocol was followed as detailed next in the 'Clinical protocol' subsection.

\section{Clinical protocol for food and supplement studies}

Volunteers were required to fast from 22.00 hours, the night before attending the clinic. Participant height, weight and blood pressure (Omron M5-I with standard cuff obtained from White Medical, Rugby, UK) were measured, a fasting

Table 1. Baseline characteristics of volunteers by intervention group in the food study

(Percentages, mean values and standard deviations)

\begin{tabular}{|c|c|c|c|c|c|}
\hline & \multicolumn{2}{|c|}{$\begin{array}{c}\text { Spinach } \\
\text { powder ( } n \text { 25) }\end{array}$} & \multicolumn{2}{|c|}{$\begin{array}{l}\text { Carrot juice } \\
\quad(n 27)\end{array}$} & \multirow[b]{2}{*}{$P$} \\
\hline & Mean & SD & Mean & SD & \\
\hline Sex (\% male) & \multicolumn{2}{|c|}{$40 \cdot 0$} & \multicolumn{2}{|c|}{33.3} & 0.62 \\
\hline Age (years) & $35 \cdot 6$ & $13 \cdot 8$ & $34 \cdot 2$ & $11 \cdot 3$ & 0.70 \\
\hline Systolic BP (mmHg) & $119 \cdot 4$ & 11.5 & $127 \cdot 0$ & $19 \cdot 8$ & 0.10 \\
\hline Diastolic BP $(\mathrm{mmHg})$ & $76 \cdot 8$ & 8.6 & $79 \cdot 7$ & $11 \cdot 1$ & 0.29 \\
\hline BMI $\left(\mathrm{kg} / \mathrm{m}^{2}\right)$ & 24.0 & 3.7 & $24 \cdot 1$ & 4.0 & 0.94 \\
\hline Current smokers (\%) & \multicolumn{2}{|c|}{$16 \cdot 0$} & \multicolumn{2}{|c|}{$18 \cdot 5$} & 0.81 \\
\hline Drink alcohol (\%) & \multicolumn{2}{|c|}{92} & \multicolumn{2}{|c|}{74} & 0.09 \\
\hline
\end{tabular}

$\mathrm{BP}$, blood pressure. 
spot urine sample collected and a fasting blood sample $(55 \mathrm{ml})$ taken. Subjects were also asked questions regarding their date of birth and other health-related habits including smoking, alcohol consumption and medication use, using a standard questionnaire.

Each subject's right pupil was dilated using a short-term dilator ( $1 \%$ tropicamide), pupil size after dilation was measured and MPL was assessed by Raman spectroscopy ${ }^{(6)}$. The Raman spectrometer was obtained from Spectrotek LC, Salt Lake City, UT, USA. Resonance Raman spectroscopy involves a low-powered $1.0 \mathrm{~mW}$ argon laser spot $(488 \mathrm{~nm})$ being directed as a $1 \mathrm{~mm}$ diameter spot onto the macular retina for $0.25 \mathrm{~s}$. The methodology exploits the spectral absorption characteristics of the macular pigment which absorbs light from about $400-500 \mathrm{~nm}$, reaching a maximum absorption at approximately $460 \mathrm{~nm}$. The laser resonantly excites the long conjugated carbon double and single bonds within the macular pigment producing two prominent stokes lines at 1159 and 1525 per $\mathrm{cm}$, which correspond to those identified from lutein and zeaxanthin dissolved in tetrahydofuran. The backscattered light is collected by a fibre-optic collection bundle and the resultant Raman spectrograph analysed by a computer program. The peak height at the carotenoid carbon-carbon double-bond stretch frequency of 1525 per $\mathrm{cm}$ is quantified after subtraction of background fluorescence by the Windows-based computer software (Eye-C-Spec; Spectrotek, LC). The Raman signal intensity is expressed as photon counts. The manufacturers recommend that to overcome the errors introduced by misalignment or blink, the mean of the highest three of the five measurements recorded at any one sitting should be used for statistical analysis (Raman count). A previous study has reported $13.5 \%$ as the CV for resonance Raman spectroscopy when carried out four times over a 2-week period ${ }^{(24)}$

Serum samples were kept in the dark for $1 \mathrm{~h}$ and separated by centrifugation. EDTA samples were stored for $1 \mathrm{~h}$ at $4{ }^{\circ} \mathrm{C}$ and separated by centrifugation. Urine sample aliquots were frozen without the addition of a preservative. All samples, including urine samples, were stored at $-80^{\circ} \mathrm{C}$ until analysis (within 2 years). All baseline and post-supplementation samples were analysed together within each assay run.

\section{Endpoint measurements}

Inter-cellular adhesion molecule 1/vascular cell adhesion molecule 1. Analysis of ICAM-1 and VCAM-1 was carried out by ELISA (Immunodiagnostic Systems Limited, Tyne and Wear, UK). Intra- and inter-batch CV for both ICAM-1 and VCAM-1 was $<3 \%$.

C-reactive protein. CRP was assessed by latex-enhanced immunoturbidimetric assay (Randox Pharmaceuticals, Crumlin, UK) using an ILab 600 biochemical analyser (Instrumentation Laboratories Limited, Warrington, UK). The inter-assay CV was $1.7 \%(n 10)$.

$F_{2}$-isoprostanes. Total urinary $F_{2}$-isoprostane concentrations were measured as an estimate of systemic oxidative stress using the method outlined by Roberts \& Morrow ${ }^{(25)}$. Following extraction, derivatised spot urine samples were

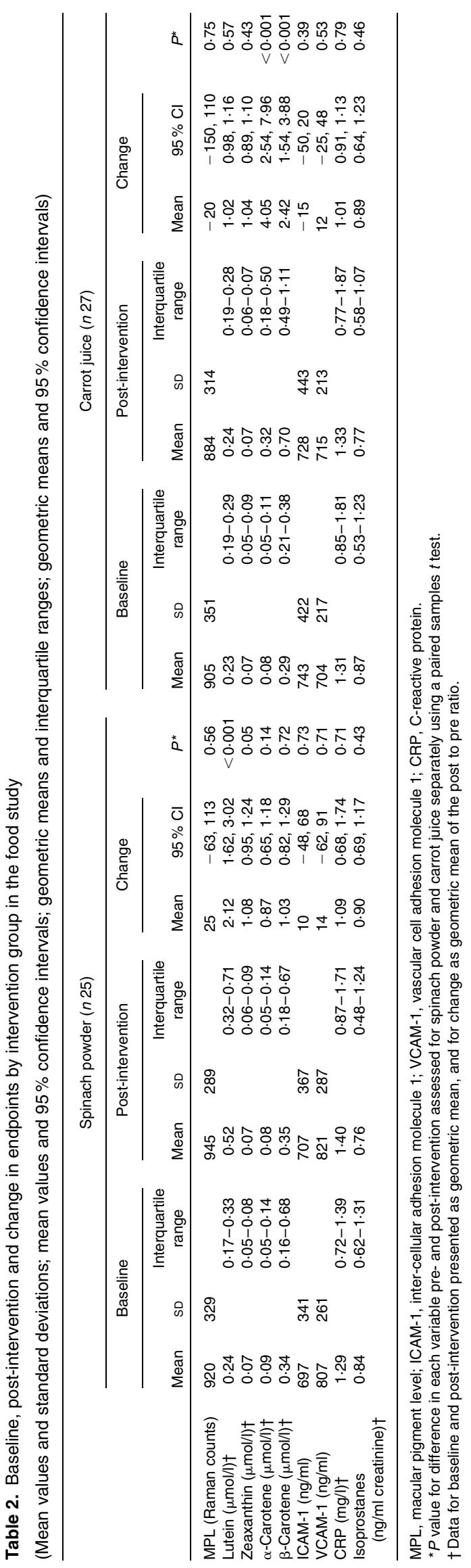


analysed by GC-MS using a Trace GC Ultra-DSQ II MS system (Thermo Fisher Scientific, Waltham, MA, USA). The inter-assay $\mathrm{CV}$ for this technique was $<12 \%$. Total $\mathrm{F}_{2}$-isoprostane content was standardised for urinary creatinine. The latter was measured using an automated enzymatic method (Randox, Crumlin, Northern Ireland, UK) on an ILab 600 biochemical analyser (ILab 600; Instrumentation Laboratories).

Vitamin $A, E$ and carotenoids. Levels of vitamin $\mathrm{A}, \mathrm{E}$ and carotenoids in serum were assessed using HPLC with diode array detection following extraction into heptane ${ }^{(23)}$. Intra- and inter-batch CV were $<10 \%$.

\section{Statistical analyses}

All statistical analyses were carried out using SPSS for Windows version 14.0. (SPSS Inc., Chicago, IL, USA)

Continuous variables were checked for normality and were logarithmically transformed where necessary. Data are presented as means and standard deviations for normally distributed data, and geometric mean (interquartile range) for logarithmically transformed data. $\chi^{2}$ tests were carried out to compare categorical variables between the intervention groups. Comparisons of baseline characteristics between two groups were made using the independent-samples $t$ test.

Comparisons between pre- and post-values in the food study were made using paired samples $t$ tests. Comparisons between three groups in the supplementation study were made using a one-way ANOVA followed by the Newman-Keuls multiplerange comparison test. Associations between two continuous variables were assessed using Pearson correlation coefficients. Analysis was conducted on an intention-to-treat basis.

\section{Results}

\section{Food study}

A total of fifty-seven volunteers (male and female) aged 22-62 years were recruited and fifty-two completed the study (the five dropouts were due to difficulty in consuming the intervention foods). Table 1 shows the baseline characteristics of the food study population by intervention group. There was no difference in any of the variables assessed between groups at baseline.

Dietary intake of the study population by the intervention group was assessed by the 4-d food diary, and was within usual population ranges. There was no difference in any of the main macro- and micronutrients assessed between groups at baseline, including carotene, and there was also no change in any of these variables during the intervention period (excluding food supplement; data not shown).

Table 2 shows that there was a significant increase in serum lutein $(P<0.001)$ and a trend towards an increase in serum zeaxanthin $(P=0.05)$ after supplementation in the spinach powder group. There were significant increases in both serum $\alpha$ - and $\beta$-carotene after supplementation $(P<0.001)$ with carrot juice. However, there was no change in MPL or in the markers of endothelial activation, inflammation or oxidation after supplementation with either spinach powder or carrot juice.

\section{Supplement study}

A total of seventy-five volunteers (male and female) aged 21-72 years were recruited and all seventy-five volunteers completed the study. Table 3 shows the baseline characteristics of the supplementation study population by the intervention group. There was no significant difference in any of the variables shown between the three groups at baseline.

Dietary intake of the study population by the intervention group was assessed by the 4-d food diary, and was within usual population ranges. There was no difference in any of the main macro- and micronutrients assessed between groups at baseline, including carotene, and there was also no difference in change in any of these variables assessed between groups during the intervention period (excluding supplement intake; data not shown).

Table 4 shows that there was a significantly larger increase in serum lutein and zeaxanthin in the lutein and zeaxanthin group, compared to the $\beta$-carotene and placebo groups $(P<0.001)$. There was also a significantly larger increase in serum $\beta$-carotene in the $\beta$-carotene group compared with the lutein and zeaxanthin, and placebo groups $(P<0.001)$. However, there was no difference in change in MPL or markers of endothelial activation, inflammation or oxidation between the intervention groups.

Further exploration of the data revealed that, although there was no significant effect of lutein and zeaxanthin supplementation or consumption of lutein- and zeaxanthin-rich

Table 3. Baseline characteristics of volunteers by intervention group in the supplement study (Percentages, mean values and standard deviations)

\begin{tabular}{|c|c|c|c|c|c|c|c|}
\hline & \multicolumn{2}{|c|}{$\begin{array}{l}\text { Lutein and zeax- } \\
\text { anthin (n 25) }\end{array}$} & \multicolumn{2}{|c|}{$\begin{array}{l}\beta \text {-Carotene } \\
(n 25)\end{array}$} & \multicolumn{2}{|c|}{$\begin{array}{l}\text { Placebo } \\
(n 25)\end{array}$} & \multirow[b]{2}{*}{$P$} \\
\hline & Mean & SD & Mean & SD & Mean & SD & \\
\hline Sex (\% male) & \multicolumn{2}{|c|}{44} & \multicolumn{2}{|c|}{32} & \multicolumn{2}{|c|}{48} & 0.49 \\
\hline Age (years) & $36 \cdot 6$ & $10 \cdot 6$ & $36 \cdot 6$ & 11.9 & $39 \cdot 6$ & $14 \cdot 2$ & 0.61 \\
\hline Systolic BP (mmHg) & 124.5 & $11 \cdot 7$ & $124 \cdot 7$ & $15 \cdot 5$ & $131 \cdot 1$ & $14 \cdot 0$ & 0.17 \\
\hline Diastolic BP (mmHg) & $79 \cdot 3$ & $7 \cdot 4$ & $78 \cdot 9$ & $8 \cdot 0$ & $80 \cdot 1$ & $10 \cdot 0$ & 0.88 \\
\hline BMI $\left(\mathrm{kg} / \mathrm{m}^{2}\right)$ & 24.5 & $3 \cdot 4$ & & 2.5 & $25 \cdot 8$ & $3 \cdot 6$ & 0.19 \\
\hline Current smokers (\%) & \multicolumn{2}{|c|}{16} & \multicolumn{2}{|c|}{20} & \multicolumn{2}{|c|}{12} & 0.74 \\
\hline Drink alcohol (\%) & \multicolumn{2}{|c|}{92} & \multicolumn{2}{|c|}{92} & \multicolumn{2}{|c|}{72} & 0.07 \\
\hline
\end{tabular}

$\mathrm{BP}$, blood pressure. 
Table 4. Baseline, post-intervention and change in endpoints by intervention group in the supplement study

(Mean values and standard deviations; mean values and $95 \%$ confidence intervals; geometric means and interquartile ranges; geometric means and $95 \%$ confidence intervals)

\begin{tabular}{|c|c|c|c|c|c|c|c|c|}
\hline & \multicolumn{8}{|c|}{ Lutein and zeaxanthin ( $n$ 25) } \\
\hline & \multicolumn{3}{|c|}{ Baseline } & \multicolumn{3}{|c|}{ Post-intervention } & \multicolumn{2}{|c|}{ Change } \\
\hline & Mean & SD & $\begin{array}{l}\text { Interquartile } \\
\text { range }\end{array}$ & Mean & SD & $\begin{array}{l}\text { Interquartile } \\
\text { range }\end{array}$ & Mean & $95 \% \mathrm{Cl}$ \\
\hline MPL (Raman counts) & 849 & 351 & & 817 & 317 & & -32 & $-142,78$ \\
\hline Lutein $(\mu \mathrm{mol} / \mathrm{l}) \dagger$ & 0.20 & & $0.15-0.29$ & 0.50 & & $0.40-0.67$ & $257^{a}$ & 215,308 \\
\hline Zeaxanthin $(\mu \mathrm{mol} / \mathrm{l}) \dagger$ & 0.06 & & $0.04-0.07$ & 0.16 & & $0.14-0.21$ & $283^{a}$ & 231,347 \\
\hline$\alpha$-Carotene $(\mu \mathrm{mol} / \mathrm{l}) \dagger$ & 0.08 & & $0.06-0.13$ & 0.08 & & $0.07-0.12$ & 111 & 94,131 \\
\hline$\beta$-Carotene $(\mu \mathrm{mol} / \mathrm{l}) \dagger$ & 0.30 & & $0.19-0.42$ & 0.35 & & $0.25-0.52$ & $117^{\mathrm{a}}$ & 101,135 \\
\hline ICAM-1 (ng/ml) & 933 & 385 & & 935 & 380 & & 2 & $-78,69$ \\
\hline VCAM-1 (ng/ml) & 812 & 224 & & 809 & 239 & & -3 & $-34,73$ \\
\hline $\operatorname{CRP}(\mathrm{mg} / \mathrm{l}) \dagger$ & 1.30 & & $0.78-2.20$ & 1.26 & & $0.81-2.02$ & 93 & 68,128 \\
\hline $\begin{array}{l}\text { Isoprostanes } \\
\text { (ng/ml creatinine) } \dagger\end{array}$ & $1 \cdot 11$ & & $0.83-1.40$ & 1.04 & & $0.78-1.42$ & 94 & 83,106 \\
\hline
\end{tabular}

\begin{tabular}{|c|c|c|c|c|c|c|c|c|}
\hline & \multicolumn{8}{|c|}{$\beta$-Carotene (n 25) } \\
\hline & \multicolumn{3}{|c|}{ Baseline } & \multicolumn{3}{|c|}{ Post-intervention } & \multicolumn{2}{|c|}{ Change } \\
\hline & Mean & SD & $\begin{array}{l}\text { Interquartile } \\
\text { range }\end{array}$ & Mean & SD & $\begin{array}{l}\text { Interquartile } \\
\text { range }\end{array}$ & Mean & $95 \% \mathrm{Cl}$ \\
\hline MPL (Raman counts) & 791 & 307 & & 776 & 311 & & -16 & $-109,77$ \\
\hline Lutein $(\mu \mathrm{mol} / \mathrm{l}) \dagger$ & 0.21 & & $0.14-0.29$ & 0.21 & & $0.15-0.27$ & $102^{\mathrm{b}}$ & 93,110 \\
\hline Zeaxanthin $(\mu \mathrm{mol} / \mathrm{l}) \dagger$ & 0.06 & & $0.05-0.09$ & 0.06 & & $0.05-0.08$ & $100^{\mathrm{b}}$ & 91,110 \\
\hline$\alpha$-Carotene $(\mu \mathrm{mol} / \mathrm{l}) \dagger$ & 0.12 & & $0.07-0.20$ & 0.12 & & $0.08-0.17$ & 105 & 93,120 \\
\hline$\beta$-Carotene $(\mu \mathrm{mol} / \mathrm{l}) \dagger$ & 0.40 & & $0.29-0.64$ & 1.03 & & $0.59-1.75$ & $256^{\mathrm{b}}$ & 195,337 \\
\hline ICAM-1 (ng/ml) & 907 & 356 & & 902 & 310 & & -4 & $-57,61$ \\
\hline VCAM-1 (ng/ml) & 818 & 220 & & 838 & 232 & & 20 & $-44,37$ \\
\hline $\mathrm{CRP}(\mathrm{mg} / \mathrm{l}) \dagger$ & 0.86 & & $0.64-1.81$ & 1.08 & & $0.69-1.68$ & 126 & 75,211 \\
\hline $\begin{array}{l}\text { Isoprostanes } \\
\text { (ng/ml creatinine }) \dagger\end{array}$ & 1.00 & & $0.72-1.49$ & 0.99 & & $0.80-1.43$ & 98 & 77,126 \\
\hline
\end{tabular}

\begin{tabular}{|c|c|c|c|c|c|c|c|c|c|}
\hline & \multicolumn{8}{|c|}{ Placebo ( $n$ 25) } & \multirow[b]{3}{*}{$P^{*}$} \\
\hline & \multicolumn{3}{|c|}{ Baseline } & \multicolumn{3}{|c|}{ Post-intervention } & \multicolumn{2}{|c|}{ Change } & \\
\hline & Mean & SD & $\begin{array}{l}\text { Interquartile } \\
\text { range }\end{array}$ & Mean & SD & $\begin{array}{l}\text { Interquartile } \\
\text { range }\end{array}$ & Mean & $95 \% \mathrm{Cl}$ & \\
\hline MPL (Raman counts) & 702 & 329 & & 688 & 323 & & -14 & $-94,67$ & 0.96 \\
\hline Lutein $(\mu \mathrm{mol} / \mathrm{l}) \dagger$ & 0.23 & & $0.18-0.29$ & 0.21 & & $0.17-0.25$ & $92^{\mathrm{b}}$ & 86,97 & $<0.001$ \\
\hline Zeaxanthin $(\mu \mathrm{mol} / \mathrm{l}) \dagger$ & 0.06 & & $0.04-0.07$ & 0.05 & & $0.04-0.06$ & $92^{\mathrm{b}}$ & 85,99 & $<0.001$ \\
\hline$\alpha$-Carotene $(\mu \mathrm{mol} / \mathrm{l}) \dagger$ & 0.08 & & $0.07-0.11$ & 0.09 & & $0.06-0.13$ & 106 & 90,124 & 0.85 \\
\hline$\beta$-Carotene $(\mu \mathrm{mol} / \mathrm{l}) \dagger$ & 0.29 & & $0.19-0.47$ & 0.28 & & $0.17-0.49$ & $98^{\mathrm{a}}$ & $85-114$ & $<0.001$ \\
\hline ICAM-1 (ng/ml) & 1088 & 408 & & 1090 & 445 & & 2 & $-40,45$ & 0.98 \\
\hline VCAM-1 (ng/ml) & 816 & 233 & & 812 & 239 & & -4 & $-51,43$ & 0.71 \\
\hline CRP $(\mathrm{mg} / \mathrm{ll}) \dagger$ & 1.34 & & $0.62-2.65$ & 1.70 & & $0.71-3.20$ & 127 & 68,236 & 0.60 \\
\hline $\begin{array}{l}\text { Isoprostanes } \\
\text { (ng/ml creatinine) } \dagger\end{array}$ & $1 \cdot 26$ & & $0.81-1.60$ & $1 \cdot 33$ & & $0 \cdot 83-1.70$ & 106 & 92,121 & $0 \cdot 60$ \\
\hline
\end{tabular}

MPL, macular pigment level; ICAM-1, inter-cellular adhesion molecule 1; VCAM-1, vascular cell adhesion molecule 1; CRP, C-reactive protein.

a,b Superscripted letters indicate homogeneous subsets.

* $P$-value for difference in change in each variable between the intervention groups assessed using one-way ANOVA.

†Data for baseline and post-intervention presented as geometric mean, and for change as geometric mean of the post to pre ratio.

foods on MPL, the increase in serum lutein and zeaxanthin over the intervention period for each study was significantly associated (lutein - supplement study), or tended to be associated (lutein - food study and zeaxanthin - both studies) with the increase in MPL. This is shown in Fig. 1. In both studies, the change in MPL was associated with baseline MPL (all subjects; food study $r-0.54, P<0.001$; supplement study $r-0 \cdot 40, P<0 \cdot 001$ ).

\section{Discussion}

This study has assessed the effects of lutein- and zeaxanthinrich foods and supplements on MPL, markers of inflammation and oxidation as biomarkers of AMD risk, in healthy subjects.

Previous observational studies have shown associations between lutein, zeaxanthin and MPL ${ }^{(26-28)}$. Due to these initial epidemiological findings suggesting that higher serum or 

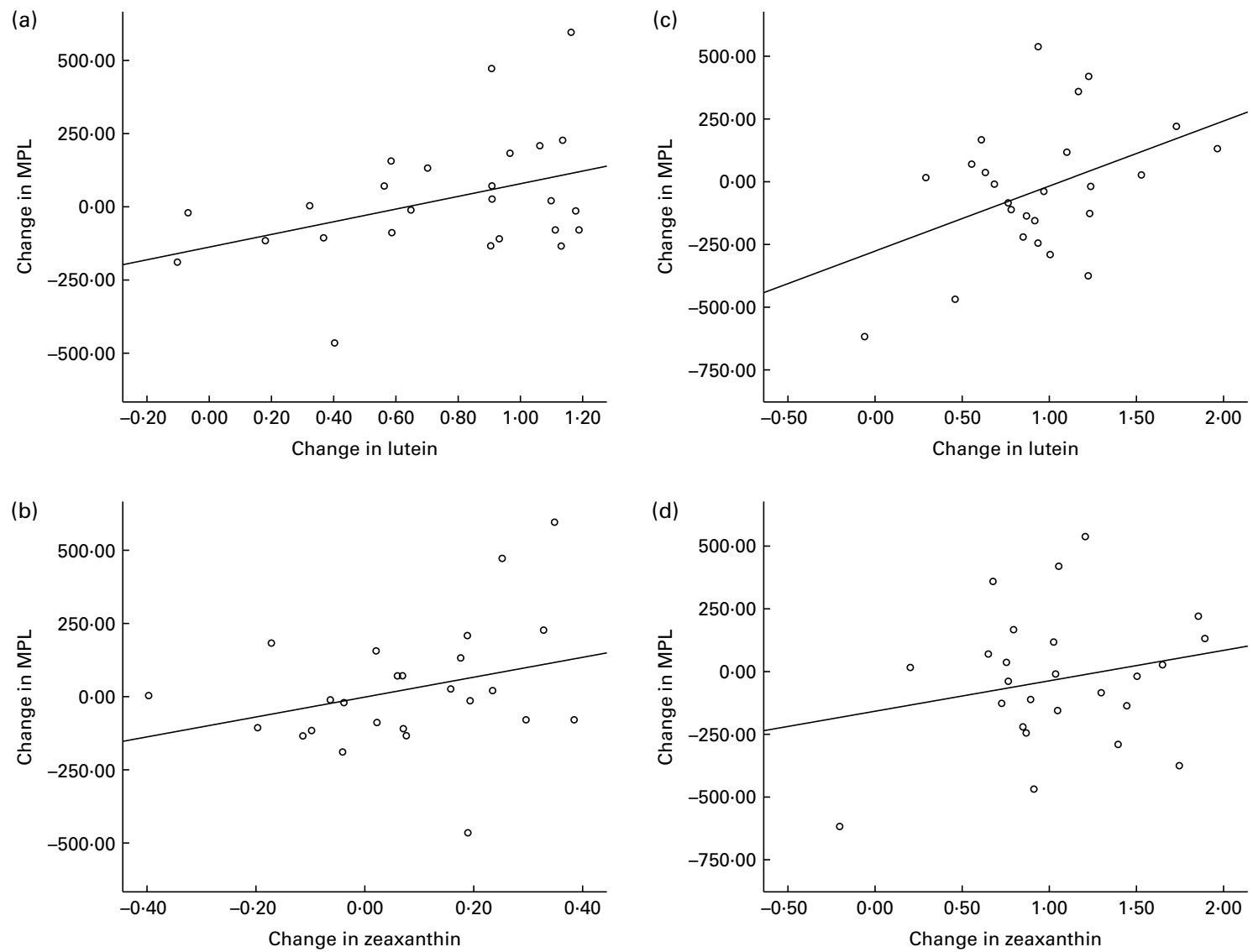

Fig. 1. Change in serum lutein and zeaxanthin $v$. change in macular pigment level (MPL) for the food study and supplement study (in the spinach powder group (food study) or lutein and zeaxanthin supplement group (supplement study). (a) Change in MPL $v$. change in lutein while consuming spinach powder ( $r 0.396$ $P=0.05 ; R^{2}$ linear 0.156); (b) change in MPL $v$. change in zeaxanthin while consuming spinach powder $\left(r 0.304, P=0.14 ; R^{2}\right.$ linear 0.092$)$; (c) change in MPL $v$. change in lutein while on lutein and zeaxanthin supplementation $\left(r 0.425, P=0.03 ; R^{2}\right.$ linear 0.181$)$; (d) change in MPL $v$. change in zeaxanthin while on lutein and zeaxanthin supplementation $\left(r 0.224, P 0.28 ; R^{2}\right.$ linear 0.05$)$.

dietary intakes of lutein and zeaxanthin are associated with higher MPL, a number of intervention trials were undertaken to determine whether supplementation with these compounds increased MPL. These studies tended to be small, and just a few have been placebo-controlled ${ }^{(29-36)}$. They also used a variety of methods to measure MPL, each with their own inherent advantages and disadvantages ${ }^{(37)}$. We chose Raman spectroscopy as our method of measurement, which has been used successfully in both healthy subjects and AMD patients $^{(6,24)}$. This technique is objective, sensitive, specific and fast, as well as being highly repeatable ${ }^{(24)}$.

There are a number of possible reasons as to why no difference in MPL was noted in response to supplementation in this study. These were pilot studies, but a retrospective power calculation, using data from participants in the present studies revealed that, with the numbers of participants we recruited, we would have had $80 \%$ power to detect as statistically significant, a change of 354 in MPL in the food study, and a difference in MPL between the intervention groups of 215 in the supplement study, indicating that these studies were underpowered, and this should guide the design of future studies. However, there are a number of other study design considerations during the planning of further studies. First, the duration of supplementation may have been insufficient;
Cardinault et $a l .^{(36)}$ did not show a change after $35 \mathrm{~d}$, and most of the studies that showed a significant response supplementation continued for at least $120 \mathrm{~d}$. Secondly, and supported by the retrospective power calculation, the sensitivity of the Raman measurement may have been unable to show small changes, given that the population variation is large. Berendschot et al. ${ }^{(31)}$ confirmed the influence of different measurement methodologies in a supplementation study that used both scanning laser ophthalmoscopy and spectral reflectance maps; $100 \%$ of participants showed an increase on the basis of the scanning laser ophthalmoscopy results, whereas only $50 \%$ showed a significant increase on the spectral reflectance maps, indicating the importance of the method of assessment of MPL.

It could also be that the findings in these studies are attributable to the volunteers being young (average age 35-38 years), health-aware (mostly from a hospital/research environment), and therefore already consuming a healthy diet with a high intake of lutein and zeaxanthin. Their MPL measurements may therefore have been initially normal, although a normal range for Raman measurements has yet to be formally defined, and the capacity for an increase in MPL through increased lutein and zeaxanthin consumption may have been minimal, particularly since the extent of the increase in the present 
study was inversely related to baseline MPL level. One of the few other studies to report Raman data that can be compared with our study reported similar MPL levels for a comparable age group (mean 1060 (SD 459) Raman counts $)^{(24)}$. Also, doses of $15 \mathrm{mg}$ of lutein and zeaxanthin in the spinach powder and lutein and zeaxanthin supplement may have been too low to affect what were already normal MPL in these healthy individuals, although others have shown an effect of similar doses ${ }^{(31,38-40)}$.

Although there were no between-group differences in MPL response over the two studies, there was some evidence, within the groups on the lutein and zeaxanthin study arms, that the increase in serum lutein and zeaxanthin was associated with the increase in MPL, and the increase in MPL was associated with baseline MPL. Evidence of 'retinal non-response' is an interesting characteristic demonstrated in many of the previous supplementation studies, with the proportion of participants showing this feature varying widely. The reasons for this occurring are not known, though various conclusions can be drawn from looking at the previous studies ${ }^{(32,33,36,38-43)}$ : it occurs in both healthy volunteers and those with retinal pathology ${ }^{(36,41)}$, it can be dependent on the methodology used ${ }^{(31)}$, the eccentricity at which the measurement is made ${ }^{(43)}$ and is sometimes associated with baseline levels of MP and serum lutein and zeaxanthin $^{(32,38,42)}$ but not always ${ }^{(32,33,39,40)}$. Other factors such as BMI and baseline fruit and vegetable, or fat intake may also affect retinal response. The studies reported here were not adequately powered to explore this issue fully. Further larger studies are therefore required over a longer supplementation period and with careful consideration of dose to determine if lutein- and zeaxanthin-rich foods or supplements increase MPL and ultimately reduce AMD risk in healthy volunteers, and also to fully characterise the factors influencing retinal non-response.

Numerous antioxidant micronutrients and dietary patterns have been associated with inflammatory markers and endothelial activation markers and may have a role in ameliorating inflammation and endothelial activation in AMD patients $^{(15,44-46)}$. However, in the present study, there was no change in CRP, ICAM-1 or VCAM-1 on lutein- and zeaxanthinor $\beta$-carotene-rich foods or supplements. It may be because initial inflammatory or activation marker status was too low for these compounds to have an effect and these findings suggest that carotenoids may have a limited role, if any, in reducing inflammation or reducing endothelial activation in healthy volunteers. Carotenoid supplementation may only be beneficial in those with higher levels of inflammatory markers at baseline. These results also reveal no differential effects of foods $v$. supplements on inflammatory markers or markers of endothelial activation.

A number of studies have examined the effects of antioxidants on oxidative stress either in fruit and vegetable interventions, or as supplements ${ }^{(47-54)}$. Most $^{(47-52)}$, although not all ${ }^{(53,54)}$, of these studies found a reduction in various measures of oxidative stress after supplementation. We, however, found no changes in isoprostanes in either the food or the supplement study. Again, it may be because the volunteers involved in the study were young, with supplementation unlikely to reduce what were already low levels of markers of oxidative stress at baseline.

\section{Conclusion}

Supplementation over an 8-week period with a food rich in lutein and zeaxanthin (spinach powder), or with a food rich in carotene (carrot juice), or with a combined lutein and zeaxanthin supplement, $v$. a $\beta$-carotene supplement or placebo, had no effect on MPL as assessed by Raman spectroscopy or markers of inflammation, endothelial activation or oxidation in healthy volunteers. However, the change in serum lutein and zeaxanthin was associated or tended to be associated with the change in MPL in the spinach powder and lutein and zeaxanthin supplement groups, while the change in MPL was associated with baseline MPL, suggesting that such interventions may improve MPL in the highest serum responders and in those with initially low MPL.

\section{Acknowledgements}

The present research was funded by the Food Safety Promotion Board (Safefood). The authors thank Walther Schoenenberger Pflanzensaftwerk GmbH, Germany for kindly donating carrot juice for the duration of the study. The study was sponsored by Queen's University Belfast. The contributions of the authors to the manuscript are as follows: I. S. Y., J. V. W. and R. G. designed the research; R. G. and R. E. H. conducted the research; J. V. W. and R. G. analysed the data; R. G., R. E. H., U. C., I. S. Y. and J. V. W. wrote the paper; and J. V. W. had primary responsibility for the final content. The authors declare that there are no conflicts of interest.

\section{References}

1. Evans JR, Fletcher AE \& Wormald RP (2004) Age-related macular degeneration causing visual impairment in people 75 years or older in Britain, an add-on study to the Medical Research Council Trial of Assessment and Management of Older People in the Community. Ophthalmology 111, 513-517.

2. Mares-Perlman JA, Fisher AI, Klein R, et al. (2001) Lutein and zeaxanthin in the diet and serum and their relation to age-related maculopathy in the third national health and nutrition examination survey. Am J Epidemiol 153, 424-432.

3. van Leeuwen R, Boekhoorn S, Vingerling JR, et al. (2005) Dietary intake of antioxidants and risk of age-related macular degeneration. JAMA 294, 3101-3107.

4. Seddon JM, Ajani UA, Sperduto RD, et al. (1994) Dietary carotenoids, vitamins A, C, and E, and advanced age-related macular degeneration. Eye Disease Case-Control Study Group. JAMA 272, 1413-1420.

5. Snellen EL, Verbeek AL, Van Den Hoogen GW, et al. (2002) Neovascular age-related macular degeneration and its relationship to antioxidant intake. Acta Ophthalmol Scand 80, 368-371.

6. Bernstein PS, Zhao DY, Wintch SW, et al. (2002) Resonance Raman measurement of macular carotenoids in normal subjects and in age-related macular degeneration patients. Ophthalmology 109, 1780-1787.

7. AREDS Study Group (2001) A randomized, placebocontrolled, clinical trial of high-dose supplementation with 
vitamins $\mathrm{C}$ and $\mathrm{E}$, beta carotene, and zinc for age-related macular degeneration and vision loss, AREDS report no. 8. Arch Ophthalmol 119, 1417-1436.

8. Beatty S, Murray IJ, Henson DB, et al. (2001) Macular pigment and risk for age-related macular degeneration in subjects from a Northern European population. Invest Ophthalmol Vis Sci 42, 439-446.

9. Iannone A, Rota C, Bergamini S, et al. (1998) Antioxidant activity of carotenoids, an electron-spin resonance study on beta-carotene and lutein interaction with free radicals generated in a chemical system.J Biochem Mol Toxicol 12, 299-304.

10. Bohm V, Puspitasari-Nienaber NL, Ferruzzi MG, et al. (2002) Trolox equivalent antioxidant capacity of different geometrical isomers of alpha-carotene, beta-carotene, lycopene, and zeaxanthin. J Agric Food Chem 50, 221-226.

11. Klein RJ, Zeiss C, Chew EY, et al. (2005) Complement factor $\mathrm{H}$ polymorphism in age-related macular degeneration. Science 308, 385-389.

12. Gold B, Merriam JE, Zernant J, et al. (2006) Variation in factor B (BF) and complement component 2 (C2) genes is associated with age-related macular degeneration. Nat Genet 38, 458-462.

13. Maller JB, Fagerness JA, Reynolds RC, et al. (2007) Variation in complement factor 3 is associated with risk of age-related macular degeneration. Nat Genet 39, 1200-1201.

14. Watzl B, Kulling SE, Moseneder J, et al. (2005) A 4-wk intervention with high intake of carotenoid-rich vegetables and fruit reduces plasma C-reactive protein in healthy, nonsmoking men. Am J Clin Nutr 82, 1052-1058.

15. Erlinger TP, Guallar E, Miller ER, et al. (2001) Relationship between systemic markers of inflammation and serum beta-carotene levels. Arch Intern Med 161, 1903-1908.

16. Izumi-Nagai K, Nagai N, Ohgami K, et al. (2007) Macular pigment lutein is antiinflammatory in preventing choroidal neovascularization. Arteriosclerosis Thromb Vasc Biol 27, $2555-2562$.

17. Sasaki M, Ozawa Y, Kurihara T, et al. (2009) Neuroprotective effect of an antioxidant, lutein, during retinal inflammation. Investigative Ophthalmol Vis Sci 50, 1433-1439.

18. LaRowe TL, Mares JA, Snodderly DM, et al. (2008) Macular pigment density and age-related maculopathy in the Carotenoids in Age-Related Eye Disease Study. An ancillary study of the women's health initiative. Ophthalmology 115, 876e1-883e1.

19. Rimm EB, Stampfer MJ, Ascherio A, et al. (1993) Vitamin E consumption and the risk of coronary heart disease in men. $N$ Engl J Med 328, 1450-1456.

20. Stampfer MJ, Hennekens CH, Manson JE, et al. (1993) Vitamin E consumption and the risk of coronary disease in women. $N$ Engl J Med 328, 1444-1449.

21. MRC/BHF Heart Protection Study Group (2002) MRC/BHF Heart Protection Study of antioxidant vitamin supplementation in 20,536 high-risk individuals, a randomised placebo-controlled trial. Lancet 360, 23-33.

22. Zureik M, Galan P, Bertrais S, et al. (2004) Effects of long-term daily low-dose supplementation with antioxidant vitamins and minerals on structure and function of large arteries. Arterioscler Thromb Vasc Biol 24, 1485-1491.

23. Craft NE (1992) Carotenoid reversed-phase high-performance liquid chromatography methods, reference compendium. Methods Enzymol 213, 185-205.

24. Hogg RE, Anderson RS, Stevenson MR, et al. (2007) In vivo macular pigment measurements, a comparison of resonance Raman spectroscopy and heterochromatic flicker photometry. Br J Ophthalmol 91, 485-490.

25. Roberts LJ \& Morrow JD (2000) Measurement of F(2)isoprostanes as an index of oxidative stress in vivo. Free Radic Biol Med 28, 505-513.
26. Ciulla TA, Curran-Celantano J, Cooper DA, et al. (2001) Macular pigment optical density in a midwestern sample. Ophthalmology 108, 730-737.

27. Broekmans WM, Berendschot TT, Klopping-Ketelaars IA, et al. (2002) Macular pigment density in relation to serum and adipose tissue concentrations of lutein and serum concentrations of zeaxanthin. Am J Clin Nutr 76, 595-603.

28. Hammond BR Jr \& Caruso-Avery M (2000) Macular pigment optical density in a Southwestern sample. Invest Ophthalmol Vis Sci 41, 1492-1497.

29. Johnson EJ, Hammond BR, Yeum KJ, et al. (2000) Relation among serum and tissue concentrations of lutein and zeaxanthin and macular pigment density. Am J Clin Nutr $\mathbf{7 1}$ 1555-1562.

30. Hammond BR Jr, Johnson EJ, Russell RM, et al. (1997) Dietary modification of human macular pigment density. Invest Ophthalmol Vis Sci 38, 1795-1801.

31. Berendschot TT, Goldbohm RA, Klopping WA, et al. (2000) Influence of lutein supplementation on macular pigment, assessed with two objective techniques. Invest Ophthalmol Vis Sci 41, 3322-3326.

32. Aleman TS, Cideciyan AV, Windsor EA, et al. (2007) Macular pigment and lutein supplementation in ABCA4-associated retinal degenerations. Invest Ophthalmol Vis Sci 48, 1319-1329.

33. Bone RA, Landrum JT, Cao Y, et al. (2007) Macular pigment response to a supplement containing meso-zeaxanthin, lutein and zeaxanthin. Nutr Metab (Lond) 4, 12.

34. Bone RA \& Landrum JT (2010) Dose-dependent response of serum lutein and macular pigment optical density to supplementation with lutein esters. Arch Biochem Biophys 504, 50-55.

35. Connolly EE, Beatty S, Thurnham DI, et al. (2010) Augmentation of macular pigment following supplementation with all three macular carotenoids, an exploratory study. Curr Eye Res 35, 335-351.

36. Cardinault N, Gorrand JM, Tyssandier V, et al. (2003) Short-term supplementation with lutein affects biomarkers of lutein status similarly in young and elderly subjects. Exp Gerontol 38, 573-582.

37. Beatty S, van Kuijk FJ \& Chakravarthy U (2008) Macular pigment and age-related macular degeneration, longitudinal data and better techniques of measurement are needed. Invest Ophthalmol Vis Sci 49, 843-845.

38. Bone RA, Landrum JT, Guerra LH, et al. (2003) Lutein and zeaxanthin dietary supplements raise macular pigment density and serum concentrations of these carotenoids in humans. J Nutr 133, 992-998.

39. Johnson EJ, Chung HY, Caldarella SM, et al. (2008) The influence of supplemental lutein and docosahexaenoic acid on serum, lipoproteins, and macular pigmentation. Am J Clin Nutr 87, 1521-1529.

40. Trieschmann M, Beatty S, Nolan JM, et al. (2007) Changes in macular pigment optical density and serum concentrations of its constituent carotenoids following supplemental lutein and zeaxanthin, the LUNA study. Exp Eye Res 84, 718-728.

41. Aleman TS, Duncan JL, Bieber ML, et al. (2001) Macular pigment and lutein supplementation in retinitis pigmentosa and Usher syndrome. Invest Ophthalmol Vis Sci 42, 1873-1881.

42. Wenzel AJ, Gerweck C, Barbato D, et al. (2006) A 12-wk egg intervention increases serum zeaxanthin and macular pigment optical density in women. J Nutr 136, 2568-2573.

43. Wenzel AJ, Sheehan JP, Gerweck C, et al. (2007) Macular pigment optical density at four retinal loci during 120 days of lutein supplementation. Ophthalmic Physiol Opt 27, $329-335$. 
44. Lopez-Garcia E, Schulze MB, Fung TT, et al. (2004) Major dietary patterns are related to plasma concentrations of markers of inflammation and endothelial dysfunction. $A m \mathrm{~J}$ Clin Nutr 80, 1029-1035.

45. Seddon JM, Gensler G, Klein ML, et al. (2006) C-reactive protein and homocysteine are associated with dietary and behavioral risk factors for age-related macular degeneration. Nutrition 22, 441-443.

46. Vine AK, Stader J, Branham K, et al. (2005) Biomarkers of cardiovascular disease as risk factors for age-related macular degeneration. Ophthalmology 112, 2076-2080.

47. Thompson HJ, Heimendinger J, Haegele A, et al. (1999) Effect of increased vegetable and fruit consumption on markers of oxidative cellular damage. Carcinogenesis 20, 2261-2266.

48. Thompson HJ, Heimendinger J, Gillette C, et al. (2005) In vivo investigation of changes in biomarkers of oxidative stress induced by plant food rich diets. J Agric Food Chem 53, 6126-6132.

49. Nelson JL, Bernstein PS, Schmidt MC, et al. (2003) Dietary modification and moderate antioxidant supplementation differentially affect serum carotenoids, antioxidant levels and markers of oxidative stress in older humans. $J$ Nutr 133, 3117-3123.

50. Thompson HJ, Heimendinger J, Sedlacek S, et al. (2005) 8-Isoprostane F2alpha excretion is reduced in women by increased vegetable and fruit intake. Am J Clin Nutr 82, $768-776$.

51. Riso P, Visioli F, Grande S, et al. (2006) Effect of a tomatobased drink on markers of inflammation, immunomodulation, and oxidative stress. J Agric Food Chem 54, 2563-2566.

52. Kiokias S \& Gordon MH (2003) Dietary supplementation with a natural carotenoid mixture decreases oxidative stress. Eur J Clin Nutr 57, 1135-1140.

53. O'Reilly JD, Mallet AI, McAnlis GT, et al. (2001) Consumption of flavonoids in onions and black tea, lack of effect on F2-isoprostanes and autoantibodies to oxidized LDL in healthy humans. Am J Clin Nutr 73, 1040-1044

54. Jacob RA, Aiello GM, Stephensen CB, et al. (2003) Moderate antioxidant supplementation has no effect on biomarkers of oxidant damage in healthy men with low fruit and vegetable intakes. J Nutr 133, 740-743. 